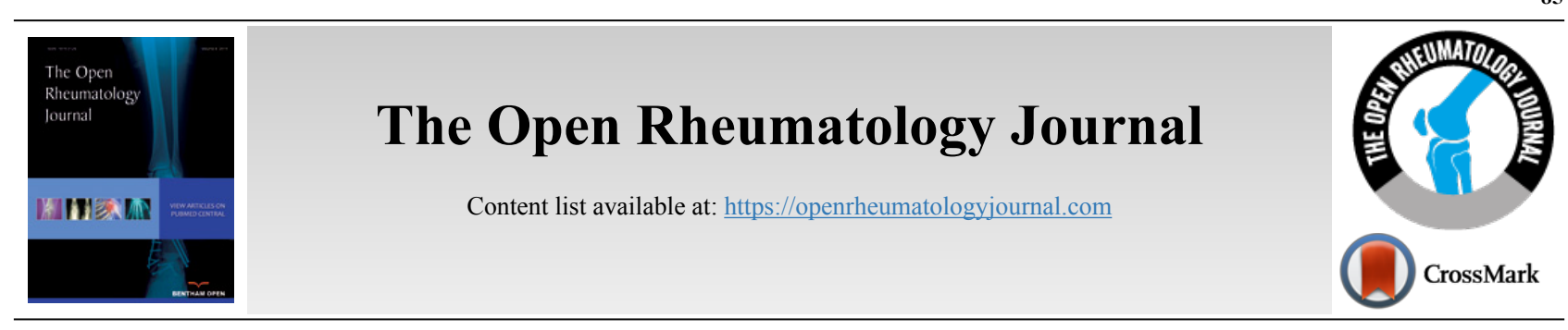

\title{
CORRIGENDUM
}

\section{Clinical Efficacy and Safety of Leflunomide in Egyptian Patients with Active Rheumatoid Arthritis: CLEAR Interim Results}

\author{
Adel El Sayed ${ }^{1, *}$, Abd El-Monim Hilal ${ }^{2}$, Ahmed Abogamal ${ }^{3}$, Alaa Labeeb ${ }^{4}$, Amin Abdel Hamid ${ }^{3}$, Amira El Gerby ${ }^{2}$, \\ Ayman Farouk Darwish ${ }^{5}$, Aziza Sayed Omar ${ }^{6}$, Dahlia Abdel Mohsen ${ }^{7}$, Dalia Faiez', A M Abda ${ }^{8}$, Fatemah A. \\ Elshabacy $^{9}$, Manal Tayel ${ }^{10}$, Mohamed Elwakd ${ }^{11}$, Mohamed Mortada ${ }^{12}$, Mohsen H.Elshahaly ${ }^{6}$, Nevine Mohannad ${ }^{10}$, Raga \\ A. Kader ${ }^{2}$, S. Z. Hassan ${ }^{11}$, Samah A. Elbakry ${ }^{7}$ and Sherif Refaat ${ }^{13}$

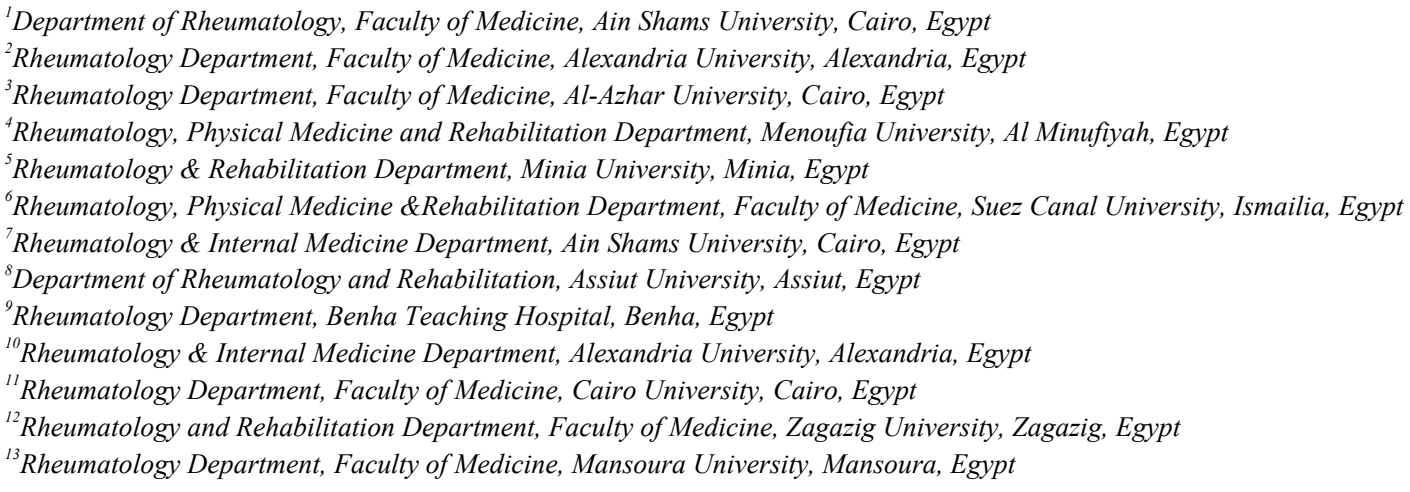

Clinical Efficacy and Safety of Leflunomide in Egyptian Patients with Active Rheumatoid Arthritis: CLEAR Interim Results

The Open Rheumatology Journal, 2018, 12: 323-331

The last paragraph on page 327 is revised as follows:

In regards to patients receiving leflunomide as a first-line therapy, the mean \pm SD CDAI total score was significantly decreased $(\mathrm{p}<0.001)$ from $35.40 \pm 16.49$ at baseline visit to reach $15.04 \pm 9.63$ after 6 weeks from treatment initiation. After additional 6 weeks, further significant decrease $(\mathrm{p}=0.028)$ was observed in the mean \pm SD CDAI total score to reach 11.83 \pm 5.88 .

The original paragraph provided is mentioned below:

In regards to patients receiving leflunomide as a first-line therapy, the mean \pm SD CDAI total score was significantly decreased $(p<0.001)$ from $35.40 \pm 16.49$ at baseline visit to reach $15.04 \pm 9.63$ after 6 weeks from treatment initiation, however after additional 6 weeks, the mean \pm SD CDAI total score was insignificantly decreased $(p=0.028)$ to be $11.83 \pm$ 5.88 .

The first paragraph on page 328 is revised as follows:

In a similar pattern, in patients receiving leflunomide as add-on therapy to other DMARDs with or without steroids, the mean \pm SD CDAI total score was significantly decreased $(p<0.001)$ from $37.09 \pm 14.12$ at baseline visit to reach 20.42 \pm 9.36 after 6 weeks from treatment initiation, and it was significantly further decreased $(\mathrm{p}<0.001)$ to reach $15.98 \pm 10.32$ after additional 6 weeks.

The original paragraph provided is mentioned below:

In patients receiving leflunomide as add-on therapy to other DMARDs with or without steroids, the mean \pm SD CDAI total score was significantly decreased from $37.09 \pm 14.12$ at baseline visit to reach $20.42 \pm 9.36$ after 6 weeks from treatment initiation. Unlike patients receiving leflunomide as a first line therapy, in this group, the mean \pm SD CDAI total score was significantly further decreased to reach $15.98 \pm 10.32$ after an additional 6 weeks.

\section{C) 2019 El Sayed et al.}

This is an open access article distributed under the terms of the Creative Commons Attribution 4.0 International Public License (CC-BY 4.0), a copy of which is available at: (https://creativecommons.org/licenses/by/4.0/legalcode). This license permits unrestricted use, distribution, and reproduction in any medium, provided the original author and source are credited. 